ARTICLE

Received 14 Sep 2016 | Accepted 28 Nov 2016 | Published 8 Feb 2017

DOI: $10.1038 /$ ncomms14085

OPEN

\title{
Unravelling exceptional acetylene and carbon dioxide adsorption within a tetra-amide functionalized metal-organic framework
}

Florian Moreau¹, Ivan da Silva², Nada H. Al Smail ${ }^{3}$, Timothy L. Easun ${ }^{4}$, Mathew Savage ${ }^{1}$, Harry G.W. Godfrey ${ }^{1}$, Stewart F. Parker ${ }^{2}$, Pascal Manuel ${ }^{2}$, Sihai Yang $^{1} \&$ Martin Schröder ${ }^{1}$

Understanding the mechanism of gas-sorbent interactions is of fundamental importance for the design of improved gas storage materials. Here we report the binding domains of carbon dioxide and acetylene in a tetra-amide functionalized metal-organic framework, MFM-188, at crystallographic resolution. Although exhibiting moderate porosity, desolvated MFM-188a exhibits exceptionally high carbon dioxide and acetylene adsorption uptakes with the latter $\left(232 \mathrm{~cm}^{3} \mathrm{~g}^{-1}\right.$ at $295 \mathrm{~K}$ and 1 bar) being the highest value observed for porous solids under these conditions to the best of our knowledge. Neutron diffraction and inelastic neutron scattering studies enable the direct observation of the role of amide groups in substrate binding, representing an example of probing gas-amide binding interactions by such experiments. This study reveals that the combination of polyamide groups, open metal sites, appropriate pore geometry and cooperative binding between guest molecules is responsible for the high uptakes of acetylene and carbon dioxide in MFM-188a.

\footnotetext{
${ }^{1}$ School of Chemistry, University of Manchester, Oxford Road, Manchester M13 9PL, UK. ${ }^{2}$ ISIS Neutron Facility, STFC Rutherford Appleton Laboratory, Chilton, Oxfordshire OX11 OQX, UK. ${ }^{3}$ School of Chemistry, University of Nottingham, Nottingham NG7 2RD, UK. ${ }^{4}$ School of Chemistry, Cardiff University, Cardiff CF10 3XQ, UK. Correspondence and requests for materials should be addressed to S.Y. (email: Sihai.Yang@manchester.ac.uk) or to M.S.

(M.Schroder@manchester.ac.uk).
} 
T he emergence of metal-organic frameworks (MOFs) as multifunctional materials results from the combination of their high porosity and precise design of pore functionality. This allows fine tuning of pore size and geometry, framework topology and chemical functionality for targeted applications such as gas storage, separation, catalysis, sensing and proton conductivity ${ }^{1-6}$. Gaining in-depth understanding and control of the supramolecular host-guest interactions is crucial if practical materials are to be developed ${ }^{7}$. Two strategies have been commonly reported to enhance the host-guest interactions in MOFs: (i) incorporation of open metal sites (OMSs); (ii) functionalization of the organic linkers to provide binding sites for guest species. The favourable role of OMSs in guest binding has been widely confirmed. For example, in situ neutron diffraction experiments for $\mathrm{D}_{2}$-loaded NOTT-101 (ref. 8) and NOTT-112 (ref. 9), $\mathrm{CO}_{2}$-loaded MOF-74Mg (ref. 10), $\mathrm{C}_{2} \mathrm{D}_{2}$-loaded HKUST-1 (ref. 11) and MOF-74Fe (ref. 12), $\mathrm{CD}_{4}$-loaded MOF-74Mg (ref. 13) and $\mathrm{D}_{2}, \mathrm{~N}_{2}$ and $\mathrm{O}_{2}$-loaded $\mathrm{Cr}^{-\mathrm{BTT}^{14}} \quad$ (BTT $^{3-}==1,3,5$-benzenetristetrazolate) clearly conclude that OMSs are the primary binding domains for guest molecules. This observation has been further evidenced by neutron spectroscopic experiments, which confirmed the large translational and/or rotational hindrance of bound guest molecules at $\mathrm{OMSs}^{15}$. In contrast, experimental investigations of the role of organic functionalization in guest binding in MOFs are scarce ${ }^{16-18}$, with the vast majority of reported examples relying predominantly on computational modelling ${ }^{19-21}$.

The amide group (-OCNH-) is of particular interest because it offers dual-functionality from both $\mathrm{CO}$ - and $\mathrm{NH}$ - sites. Notably, the introduction of amide groups in MOFs has been reported to strengthen the host-guest interactions in MOFs $^{19,22,23}$. However, experimental observation of the precise role of amides in guest binding in MOFs is still largely lacking. Here we report the synthesis, crystal structure and gas uptake properties of the tetra-amide tetra-isophthalate $\mathrm{Cu}^{11}$ complex MFM-188 (MFM, Manchester Framework Material), which exhibits an exceptionally high $\mathrm{CO}_{2}$ uptake $\left(120 \mathrm{~cm}^{3} \mathrm{~g}^{-1}\right.$ at $298 \mathrm{~K}$ and $1.0 \mathrm{bar}$ ), and significantly, a record high $\mathrm{C}_{2} \mathrm{H}_{2}$ uptake $\left(232 \mathrm{~cm}^{3} \mathrm{~g}^{-1}\right.$ at $295 \mathrm{~K}$ and $\left.1.0 \mathrm{bar}\right)$ among porous MOFs under the same conditions. Gas binding is investigated by a combination of neutron powder diffraction (NPD) and inelastic neutron scattering (INS) for both $\mathrm{CO}_{2^{-}}$and $\mathrm{C}_{2} \mathrm{H}_{2}$-loaded MFM-188. These crystallographic and dynamic experiments successfully establish a detailed molecular mechanism for guest binding at a crystallographic resolution.

\section{Results}

Synthesis and structural determination of MFM-188. The

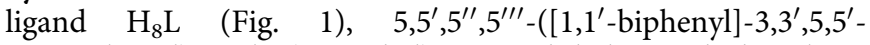
tetracarbonyl)tetrakis(azanediyl)tetraisophthalic acid, has been designed and synthesized (Supplementary Fig. 1). Single crystals of MFM-188 were obtained by solvothermal reaction of $\mathrm{CuCl}_{2}$ and $\mathrm{H}_{8} \mathrm{~L}($ ratio $=5: 1)$ in a acidic $(\mathrm{HCl})$ mixture of dimethyl sulfoxide/ $N, N$-diethylformamide/ethanol/ $\mathrm{H}_{2} \mathrm{O} \quad$ (v:v:v:v $=1: 2: 1: 1$ ) at $80^{\circ} \mathrm{C}$ for $36 \mathrm{~h}$. MFM- 188 was isolated as uniform blue squareplate crystals (size of $0.14 \times 0.14 \times 0.01 \mathrm{~mm}$ ) in a yield of $64 \%$. MFM-188 crystallizes in the space group P4/mnc [ $a=18.6861(7)$ $\AA ; \quad c=34.6960(18) \AA]$. The dihedral angle between each isophthalate and the main plane of the biphenyl core is $75.3^{\circ}$ (Supplementary Fig. 1b), with each $\mathrm{L}^{8-}$ ligand linking to eight $\left\{\mathrm{Cu}_{2}\right\}$ paddle-wheels, which each connect to four independent ligands to afford a three-dimensional (3D) open framework $\left[\mathrm{Cu}_{4}\left(\mathrm{OH}_{2}\right)_{4} \mathrm{~L}\right]$ (Supplementary Data 1). In terms of topology, the ligand can be viewed as an ensemble of three-connected (3-c) nodes: two for the biphenyl core and four corresponding to the isophthalate moieties, with the $\left\{\mathrm{Cu}_{2}\right\}$ paddle-wheels serving as four-connected $(4-c)$ nodes. Thus, the underlying trinodal $(3,3,4-c)$ net with stoichiometry $(3-c)_{2}(3-c)(4-c)$ presents a rare example of the $l w g$ topology (Supplementary Fig. 2) ${ }^{24}$.

The structure of MFM-188 can be viewed as 3D alternate packing of three types of metal-ligand cages (denoted as $\boldsymbol{A}, \boldsymbol{B}$ and $\boldsymbol{C}$ ) (Fig. 2a). The smallest cage $\boldsymbol{A}$ is comprised of four $\left\{\mathrm{Cu}_{2}\right\}$ paddle-wheels and two ligands, and has an elongated, distorted octahedral geometry (internal size of $\sim 9.4 \times 9.4 \times 13.4 \AA$ ). The $\left\{\mathrm{Cu}_{2}\right\}$ paddle-wheels occupy the four equatorial vertices with two biphenyl cores from the ligands occupying the apical vertices. Corner-sharing of cages $\boldsymbol{A}$ with biphenyl groups running along the $c$ axis and with paddle-wheels along the $a / b$ axis extends the structure (Fig. 2b). Two further distorted cuboctahedral cages $(\boldsymbol{B}$ and $\boldsymbol{C})$ result from this assembly, each comprising of eight $\left\{\mathrm{Cu}_{2}\right\}$ paddle-wheels and four ligands. The length of cage $C$, defined by the separation between the centroids of the two closest $\left\{\mathrm{Cu}_{2}\right\}$ paddle-wheels along the $c$ direction, is $17.4 \AA$. Each $\mathrm{Cu}^{\mathrm{II}}$ site has a coordinated water molecule at the axial position and points to the centre of Cage $\boldsymbol{C}$. Cages $\boldsymbol{B}$ and $\boldsymbol{C}$ are connected through shared lozenge-shaped windows on the $a b$ plane and through their apical square-shaped windows along the $c$ direction. Taking the van der Waals radii into account, cages $\boldsymbol{B}$ and $\boldsymbol{C}$ have internal pore size of $\sim 11 \times 11 \times 17 \AA$ and $\sim 17 \times 17 \times 17 \AA$, respectively. Each cage $\boldsymbol{B}$ and $\boldsymbol{C}$ is surrounded by eight cages $\boldsymbol{A}$, while each cage $\boldsymbol{A}$ is surrounded by four cages $\boldsymbol{B}$ and four cages $\boldsymbol{C}$, with cages $\boldsymbol{A}, \boldsymbol{B}$ and $\boldsymbol{C}$ present in a 2:1:1 ratio. The total accessible volume of MFM-188 upon removal of guest solvents is $73 \%$ using the PLATON/VOID routine ${ }^{25}$. Within the void space of MFM-188, there is a high concentration of amide (-OCNH-) groups pointing into cage $\boldsymbol{B}$ (O-centres) and into cage $C$ (N-H centres), thus endowing these cages with a combination of open metal sites and multiple functional groups. In contrast, none of the amide groups protrude into cage $\boldsymbol{A}$, which is functionalized solely with phenyl rings.

Characterization of MFM-188. The purity of bulk MFM-188 material was confirmed by powder X-ray diffraction (Supplementary Fig. 3) and elemental analysis. Activated MFM-188a was prepared by solvent exchange with methanol and then flowing supercritical $\mathrm{CO}_{2}$ through the sample for $12 \mathrm{~h}$ followed by heating at $100^{\circ} \mathrm{C}$ under dynamic vacuum for $20 \mathrm{~h}$. $\mathrm{N}_{2}$ adsorption at $77 \mathrm{~K}$ shows a reversible type I isotherm<smiles>O=C(O)c1cc(NC(=O)c2cc(NC(=O)c3cc(NC(=O)c4cc(C(=O)O)cc(C(=O)Nc5cc(C(=O)O)cc(C(=O)Nc6cc(C(=O)O)cc(C(=O)O)c6)c5)c4)cc(C(=O)O)c3)cc(C(=O)O)c2)cc(C(=O)O)c1</smiles>

Figure 1 | The tetra-amide octacarboxylate linker. Chemical structure of the tetra-amide octacarboxylate linker used in the synthesis of MFM-188. 
a
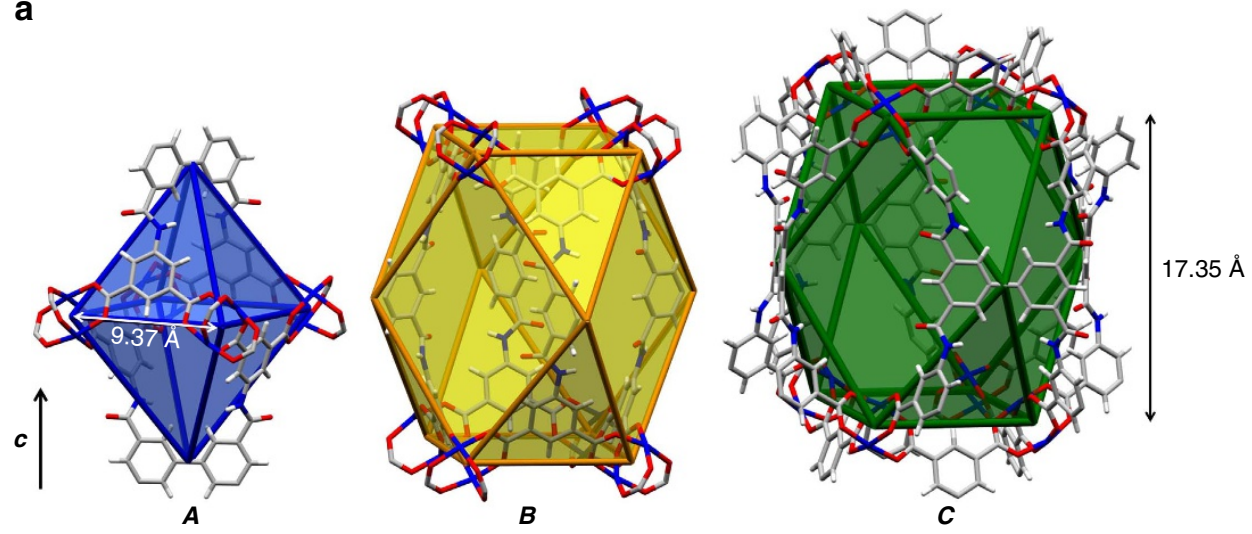

b

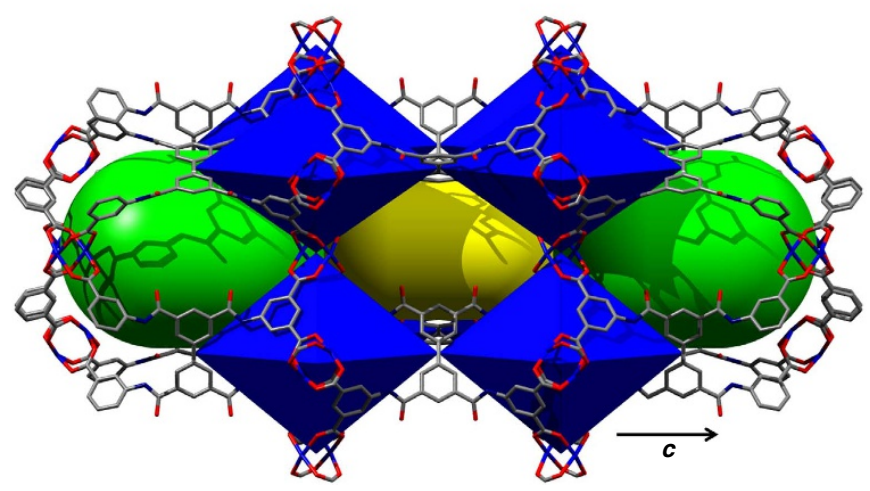

Figure 2 | View of the crystal structure of MFM-188. (a) Polyhedral representation of the three types of cages: $\boldsymbol{A}$ (octahedral), $\boldsymbol{B}$ and $\mathbf{C}$ (cuboctahedral). (b) The assembly of these cages in 3D space forming the MFM-188 framework. Cages $\boldsymbol{A}, \boldsymbol{B}$ and $\boldsymbol{C}$ are highlighted in blue, yellow and green, respectively.

(Supplementary Fig. 4) for MFM-188 with a Brunauer Emmett Teller surface area of $2568 \mathrm{~m}^{2} \mathrm{~g}^{-1}$ (Supplementary Fig. 5). The pore size distribution, calculated using a non-local density functional theory model, reveal two broad peaks centred at 12.5 and $14.7 \AA$, in good agreement with the pore size measured for cages $\boldsymbol{A}, \boldsymbol{B}$ and $\boldsymbol{C}$. Importantly, the total pore volume measured from the $\mathrm{N}_{2}$ isotherm $\left(1.12 \mathrm{~cm}^{3} \mathrm{~g}^{-1}\right)$ compares favourably with that $\left(1.07 \mathrm{~cm}^{3} \mathrm{~g}^{-1}\right)$ calculated from the X-ray crystal structure, confirming complete activation of the material. The overall porosity of MFM-188a is moderate in comparison with the most porous MOFs reported to date ${ }^{26}$.

$\mathrm{CO}_{2}$ and $\mathrm{C}_{2} \mathrm{H}_{2}$ adsorption analysis. The uptake of $\mathrm{CO}_{2}$ and $\mathrm{C}_{2} \mathrm{H}_{2}$ by activated MFM-188a was investigated up to $1 \mathrm{bar}$, and in both cases the isotherms show fully reversible adsorption with a $\mathrm{CO}_{2}$ uptake of $120 \mathrm{~cm}^{3} \mathrm{~g}^{-1}(23.7 \mathrm{wt} \%$ or $86.7 \mathrm{v} / \mathrm{v})$ recorded at $298 \mathrm{~K}$ and a $\mathrm{C}_{2} \mathrm{H}_{2}$ uptake of $232 \mathrm{~cm}^{3} \mathrm{~g}^{-1}(27.0 \mathrm{wt} \%$ or $166.7 \mathrm{v} / \mathrm{v})$ at $295 \mathrm{~K}$ (Fig. 3a). Importantly, these gravimetric uptakes are amongst the highest reported (Table 1), and are only outperformed in the case of $\mathrm{CO}_{2}$ adsorption by MOF-74Co (30.6 wt\%) and MOF-74Mg $(35.2 \mathrm{wt} \%)^{27}$, both of which present a narrower pore channel and a much higher density of OMSs (MOF-74Co: $6.4 \mathrm{mmol} \mathrm{g}^{-1}$; MOF-74Mg: $8.2 \mathrm{mmolg}^{-1}$; MFM-188: $3.3 \mathrm{mmolg}^{-1}$ ). Interestingly, MFM-188a shows the highest $\mathrm{CO}_{2}$ uptake of other amide-functionalized MOFs

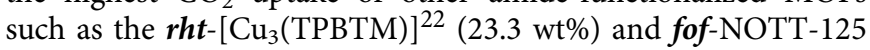
(ref. 19) (18.2 wt\%). The $\mathrm{CO}_{2}$ uptake of MFM-188a at 0.15 bar is $3.9 \mathrm{wt} \%$. To the best of our knowledge, the gravimetric capacity of $\mathrm{C}_{2} \mathrm{H}_{2} \quad(27.0 \mathrm{wt} \%)$ in MFM-188a represents the highest value observed to date for porous solids, exceeding FJI-H8 (ref. 11 (26.0 wt\%)), NJU-Bai-17 (ref. 23 (25.8 wt\%)), HKUST-1 (ref. $28(23.3 \mathrm{wt} \%)$ ) and SIFSIX-1-Cu ${ }^{29}$ (22.1 wt\%). The $\mathrm{CO}_{2}$ and $\mathrm{C}_{2} \mathrm{H}_{2}$ uptake capacity in MFM-188a increase considerably at $273 \mathrm{~K}$ to $217 \mathrm{~cm}^{3} \mathrm{~g}^{-1}(42.9 \mathrm{wt} \%)$ and $297 \mathrm{~cm}^{3} \mathrm{~g}^{-1}$ (34.5 wt\%), respectively.

The $Q_{\text {st }}$ values at zero coverage determined by virial analysis of adsorption isotherms (Supplementary Figs 6 and 7) are moderate but comparable to typical $\mathrm{Cu}^{\mathrm{II}}$ MOFs where adsorption of gas molecules occurs primarily on $\mathrm{OMSs}^{21-23,28,30}$, with $Q_{\mathrm{st}}\left(\mathrm{CO}_{2}\right)=21.0 \mathrm{~kJ} \mathrm{~mol}^{-1}$ and $Q_{\mathrm{st}} \quad\left(\mathrm{C}_{2} \mathrm{H}_{2}\right)=32.5 \mathrm{~kJ} \mathrm{~mol}^{-1}$. Interestingly, the $Q_{\text {st }}$ plots do not display any major decrease across the whole adsorption range (Fig. 3b), suggesting the presence of other favourable binding sites in addition to OMSs. We were thus motivated to investigate further the role of amides and OMSs in $\mathrm{CO}_{2}$ and $\mathrm{CH}_{2}$ adsorption in MFM-188a.

Determination of adsorption domains for $\mathrm{CO}_{2}$ and $\mathrm{C}_{2} \mathrm{H}_{2}$. The locations of adsorbed $\mathrm{CO}_{2}$ and $\mathrm{C}_{2} \mathrm{D}_{2}$ molecules within desolvated MFM-188a were determined by in situ NPD as a function of gas loading. NPD patterns were recorded at $7 \mathrm{~K}$ for the desolvated material (Supplementary Fig. 8) and at loadings of $1.75 \mathrm{CO}_{2} / \mathrm{Cu} \quad\left(127 \mathrm{~cm}^{3} \mathrm{~g}^{-1}\right) \quad$ (Supplementary Fig. 9) and $3.2 \mathrm{C}_{2} \mathrm{D}_{2} / \mathrm{Cu}\left(234 \mathrm{~cm}^{3} \mathrm{~g}^{-1}\right)$ (Supplementary Fig. 10), which correspond to the adsorption uptakes at 1 bar and room temperature for the respective gas species. Fourier difference map analysis of the NPD data of the desolvated MFM-188a indicates no residual nuclear density peak in the pore, thus confirming the complete activation and structural integrity of the desolvated sample (Supplementary Data 2). Loading of $\mathrm{CO}_{2}$ or $\mathrm{C}_{2} \mathrm{D}_{2}$ in MFM-188a was accompanied by significant changes in the relative peak intensities of the diffraction patterns. Successive Fourier difference map analysis followed by Rietveld refinement allowed identification of the position, occupancy and orientation 
Table 1 | Comparison of $\mathrm{CO}_{2} / \mathrm{C}_{2} \mathrm{H}_{2}$ uptakes and $Q_{\text {st }}$ with the density of OMSs and functional groups ${ }^{\star}$ for selected $M O F s$.

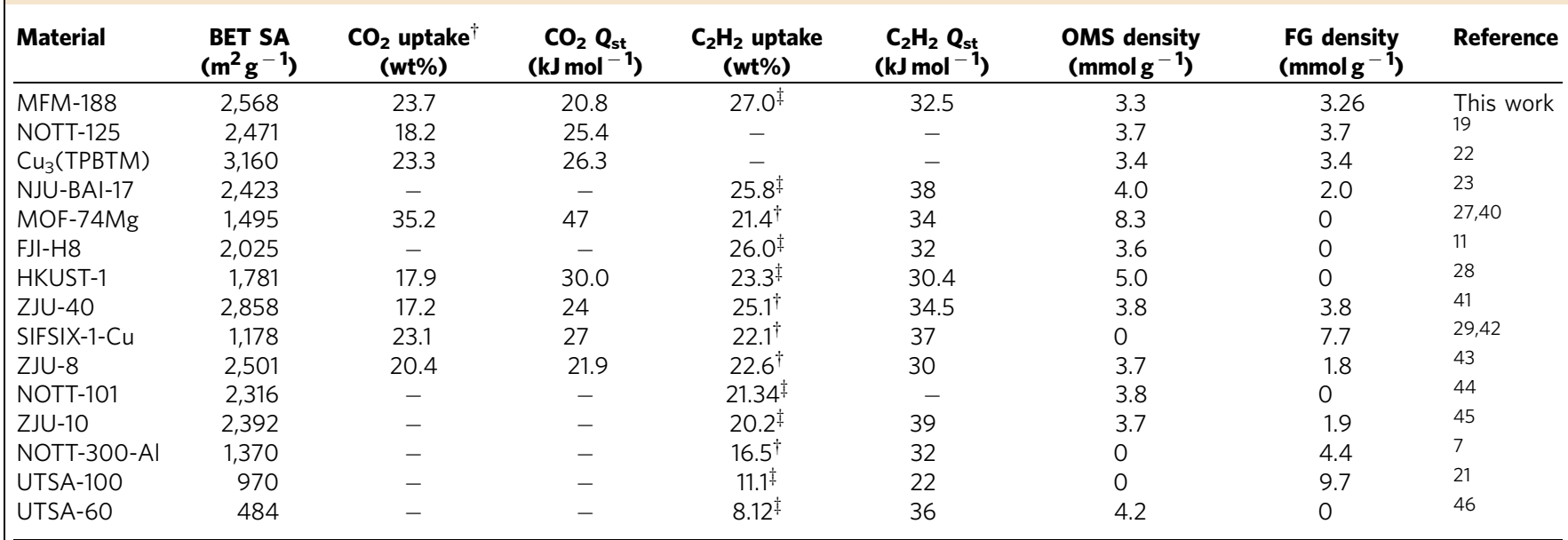

FG, functional group; MOFs, metal-organic frameworks; OMS, open metal site; SA, surface area.

*Functional groups: MFM-188, amide; NOTT-125, oxamide (considered as two equivalents of amide); [Cu군. TPBTM)], amide; NJU-BAI-17, amide; ZJU-40, pyridyl; SIFSIX-1-Cu, fluorine; ZJU-8, amine, ZJU-10, hydroxyl; NOTT-300-Al, hydroxyl; UTSA-100, amine and tetrazolyl.

$298 \mathrm{~K}$ and 1.0 bar.

$\mp 295 \mathrm{~K}$ and 1.0 bar.
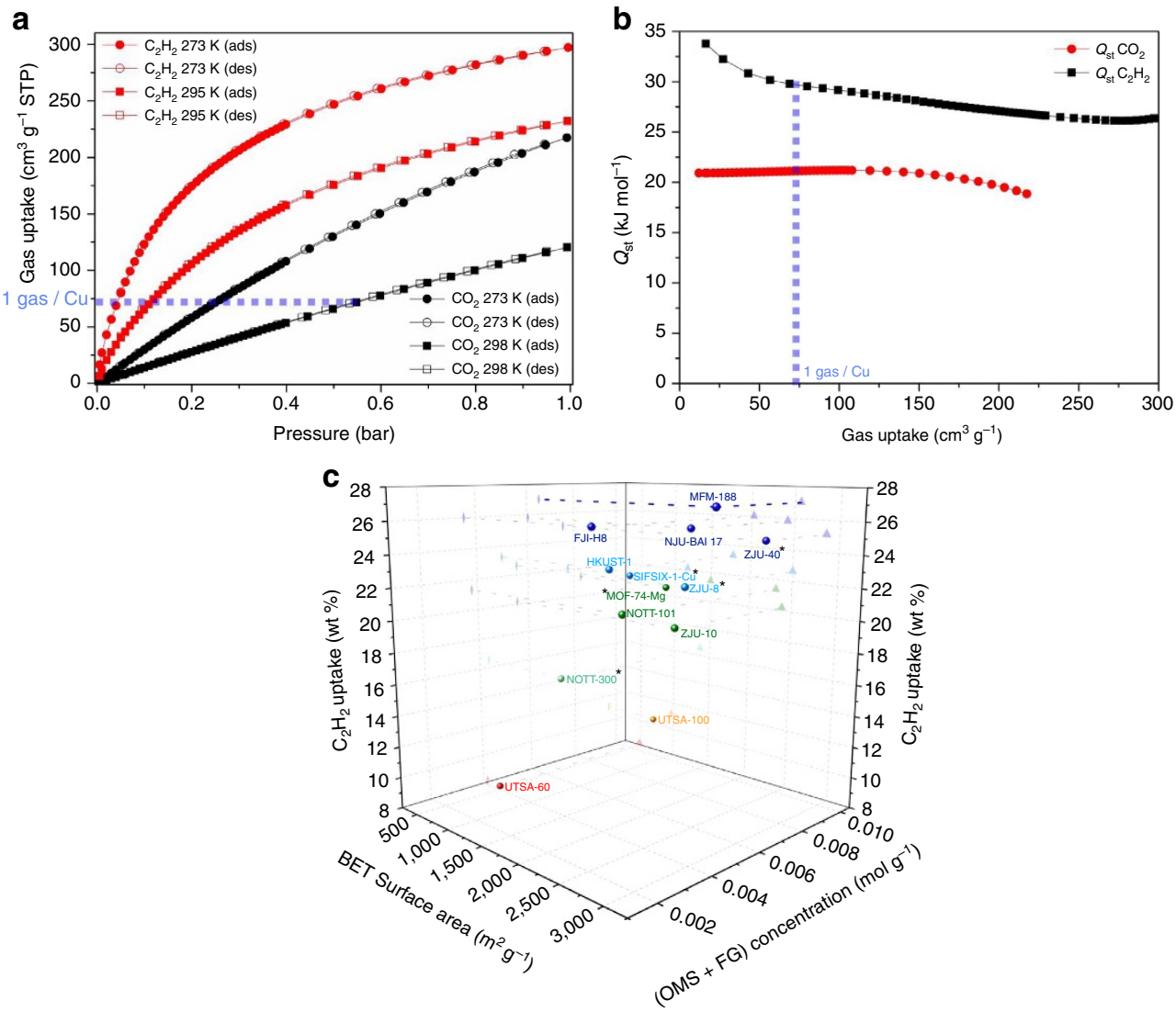

Figure 3 | Gas adsorption isotherms for MFM-188a. (a) Comparison of the $\mathrm{CO}_{2}$ and $\mathrm{C}_{2} \mathrm{H}_{2}$ adsorption isotherms for MFM-188a at 273-298 K and 1.0 bar. (b) Variation of the isosteric heats of adsorption for $\mathrm{CO}_{2}$ and $\mathrm{C}_{2} \mathrm{H}_{2}$ adsorption in MFM-188a. (c) $3 \mathrm{D}$ plot of $295 \mathrm{~K} \mathrm{C}_{2} \mathrm{H}_{2}$ uptake as a function of BET surface area and total gravimetric concentration of open metal sites and functional groups for selected MOFs. For clarity, only the best-behaving and representative MOFs are shown in the plot ( ${ }^{*}$ data were obtained at $298 \mathrm{~K}$ ). 
for adsorbed gas molecules within the framework cages (Supplementary Data 3 and 4). In both cases, six different sites $(1,2,3,4,5$ and 6 in the order of decreasing occupancy) were observed for adsorbed guest molecules: one in cage $\boldsymbol{A}$, one in cage $\boldsymbol{B}$ and four in cage $\boldsymbol{C}$, all of them having the same crystallographic multiplicity (Fig. 4). Notably, $83 \%$ of loaded $\mathrm{CO}_{2}$ and $72 \%$ of loaded $\mathrm{C}_{2} \mathrm{D}_{2}$ molecules were found in cage $C$, which contains open $\mathrm{Cu}^{\mathrm{II}}$ sites and the $\mathrm{N}-\mathrm{H}$ sites of amides pointing to the centre of the cage. The smallest cage $A$ plays a different role in $\mathrm{CO}_{2}$ and $\mathrm{C}_{2} \mathrm{D}_{2}$ uptakes with a minimum contribution to the $\mathrm{CO}_{2}$ adsorption, but considerable effect to the $\mathrm{C}_{2} \mathrm{D}_{2}$ binding.

In the structure of MFM-188.7CO site $\mathbf{1}$ bind at OMSs in cage $\boldsymbol{C}$ (occupancy $=0.52$ ). The linear body of $\mathrm{CO}_{2}(\mathbf{1})$ is perpendicular to the $\mathrm{Cu}-\mathrm{Cu}$ axis with $\mathrm{C}_{\mathrm{CO}_{2}} \cdots \mathrm{Cu}=2.35(3), \mathrm{O}_{\mathrm{CO}_{2}} \cdots \mathrm{Cu}=2.34(3) \AA$ (Fig. 5a). The second most populated site 2 (occupancy $=0.42$ ) is also located in cage $C$ where adsorbed $\mathrm{CO}_{2}$ molecules form $\mathrm{H}$-bonds with both the free amide groups (-NH) and the adjacent isophthalate $-\mathrm{CH}$ groups $\left[\mathrm{N} \cdots \mathrm{O}_{\mathrm{CO}_{2}}=2.66(6) \AA\right.$, $<\mathrm{N}-\mathrm{H} \cdots \mathrm{O}=109^{\circ} ; \quad \mathrm{C} \cdots \mathrm{O}_{\mathrm{CO}_{2}}=2.75(4) \AA \AA \quad<\mathrm{C}-\mathrm{H} \cdots \mathrm{O}=$ $141^{\circ}$ ] (Fig. 5b). $\mathrm{CO}_{2}(3)$ and $\mathrm{CO}_{2}(4)$ are also found in cage $C$ (occupancy $=0.25$ for both) at the centre of the cage and forming weak supramolecular interaction to isophthalate - $\mathrm{CH}$ groups $\left[\mathrm{C} \cdots \mathrm{O}_{\mathrm{CO}_{2}}=3.66(6) \quad \AA, \quad<\mathrm{C}-\mathrm{H} \cdots \mathrm{O}=156^{\circ}\right] \quad$ (Fig. $5 \mathrm{c}, \mathrm{d}$ ). The remaining $\mathrm{CO}_{2}(5)$ and $\mathrm{CO}_{2}(6)$ sites are found in cage $\boldsymbol{B}$ and $\boldsymbol{A}$ (occupancy $=0.19$ and 0.11 , respectively). Given the long distances between $\mathrm{CO}_{2}(5) / \mathrm{CO}_{2}(6)$ and the framework surface (above $5 \AA$ ), no specific binding interaction could be identified, thus excluding the presence of dipole interactions between the amide $-\mathrm{C}=\mathrm{O}$ and adsorbed $\mathrm{CO}_{2}$ molecules in cage $\boldsymbol{B}$.

MFM-188 $12.8 \mathrm{C}_{2} \mathrm{D}_{2}$ exhibits a different distribution of adsorbed $\mathrm{C}_{2} \mathrm{D}_{2}$ molecules within the cages, indicating the presence of different gas-sorbent binding mechanisms. The OMSs are fully occupied by $\mathrm{C}_{2} \mathrm{D}_{2}(\mathbf{1})$ molecules with a side-on interaction between the $\mathrm{C} \equiv \mathrm{C}$ bond and the $\mathrm{Cu}^{\mathrm{II}}$ centre, $\mathrm{Cu} \cdots \mathrm{C}=2.60(3), \quad 2.37(3) \AA \quad$ (Fig. 5e), similar to those determined for $\mathrm{C}_{2} \mathrm{D}_{2}$-loaded HKUST-1 (ref. 28). $\mathrm{C}_{2} \mathrm{D}_{2}(2)$ and $\mathrm{C}_{2} \mathrm{D}_{2}(3)$ are found in cage $\boldsymbol{C}$ and $\boldsymbol{A}$, respectively, (same site occupancy of 0.67$). \mathrm{C}_{2} \mathrm{D}_{2}(2)$ forms $\mathrm{H}$-bonds via its $\mathrm{C} \equiv \mathrm{C}(\delta-) \pi$ electrons to the $\mathrm{N}-\mathrm{H}$ groups pointing into the pore $\left[\mathrm{N} \cdots \mathrm{C}_{\mathrm{C} 2 \mathrm{H} 2}=3.24(5) \AA,<\mathrm{N}-\mathrm{H} \cdots \mathrm{C}=147^{\circ}\right]$ and electrostatic supramolecular interactions with the $\mathrm{C}-\mathrm{H}$ groups from the adjacent isophthalate group $\left[\mathrm{C} \cdots \mathrm{C}_{\mathrm{C} 2 \mathrm{H} 2}=3.47(1) \AA\right.$, $<\mathrm{C}-\mathrm{H} \cdots \mathrm{C}=149^{\circ}$. Significantly, this represents the first example of formation of $\mathrm{H}$-bonding between the $\mathrm{C}_{2} \mathrm{H}_{2}$ and an amide group in the solid state. $\mathrm{C}_{2} \mathrm{D}_{2}(3)$ is located at the triangular window of the smallest octahedral cage $A$ where $\mathrm{C}_{2} \mathrm{D}_{2}$ molecules are $\mathrm{H}$-bonded to carboxylate oxygen atoms $\left[\mathrm{C}_{\mathrm{C} 2 \mathrm{H} 2} \cdots \mathrm{O}=3.72(4), 3.37(4) \AA ⿻ \quad<\mathrm{C}-\mathrm{D} \cdots \mathrm{O}=143^{\circ}, 169^{\circ}\right]$ (Fig. 5f). In addition, the combination of $\mathrm{C}_{2} \mathrm{D}_{2}(\mathbf{1})$ and $\mathrm{C}_{2} \mathrm{D}_{2}(2)$ generates another adsorption site (4) with an occupancy of 0.49 in cage $C$, stabilized via the intermolecular $\mathrm{C}_{2} \mathrm{D}_{2} \cdots \mathrm{C}_{2} \mathrm{D}_{2}$ dipole interactions (Fig. 5e). Specifically, $\mathrm{C}_{2} \mathrm{D}_{2}(4)$ is perpendicular to $\mathrm{C}_{2} \mathrm{D}_{2}(\mathbf{1})$ and strong intermolecular $\mathrm{H}$-bonding is observed between these two sites $\left[C^{4} \ldots C^{1}=2.58(5) \AA\right.$, $\left.<\mathrm{C}-\mathrm{D}^{4} \cdots \mathrm{C}^{1}=164^{\circ}\right] . \mathrm{C}_{2} \mathrm{D}_{2}(4)$ is reinforced by $\mathrm{C}_{2} \mathrm{D}_{2}(2)$ through $\pi \cdots \pi$ interactions of $3.76(1) \AA$ and a dihedral angle of $84^{\circ} . \mathrm{C}_{2} \mathrm{D}_{2}(5)$ and $\mathrm{C}_{2} \mathrm{D}_{2}(6)$ are found in cage $\boldsymbol{B}$ and $\boldsymbol{C}$, respectively, (occupancy of 0.22 for both) and without specific binding interaction to the MOF host. Thus, $\mathrm{C}_{2} \mathrm{D}_{2}$ displays a dual role behaving as an $\mathrm{H}$-acceptor from amides $\mathrm{N}-\mathrm{H}$ and aromatic $\mathrm{C}-\mathrm{H}$ groups, but a $\mathrm{H}$-donor to the carboxylate oxygen, thus enhancing the $\mathrm{C}_{2} \mathrm{D}_{2}$-MOF-binding strength. In contrast, $\mathrm{CO}_{2}$ participates in $\mathrm{H}$-bond formation as an acceptor only. The highly cooperative binding of acetylene at both the open $\mathrm{Cu}^{\mathrm{II}}$ sites and free amides, coupled with the well-defined micropore windows, leads to the record high $\mathrm{C}_{2} \mathrm{H}_{2}$ adsorption capacity in MFM-188a.
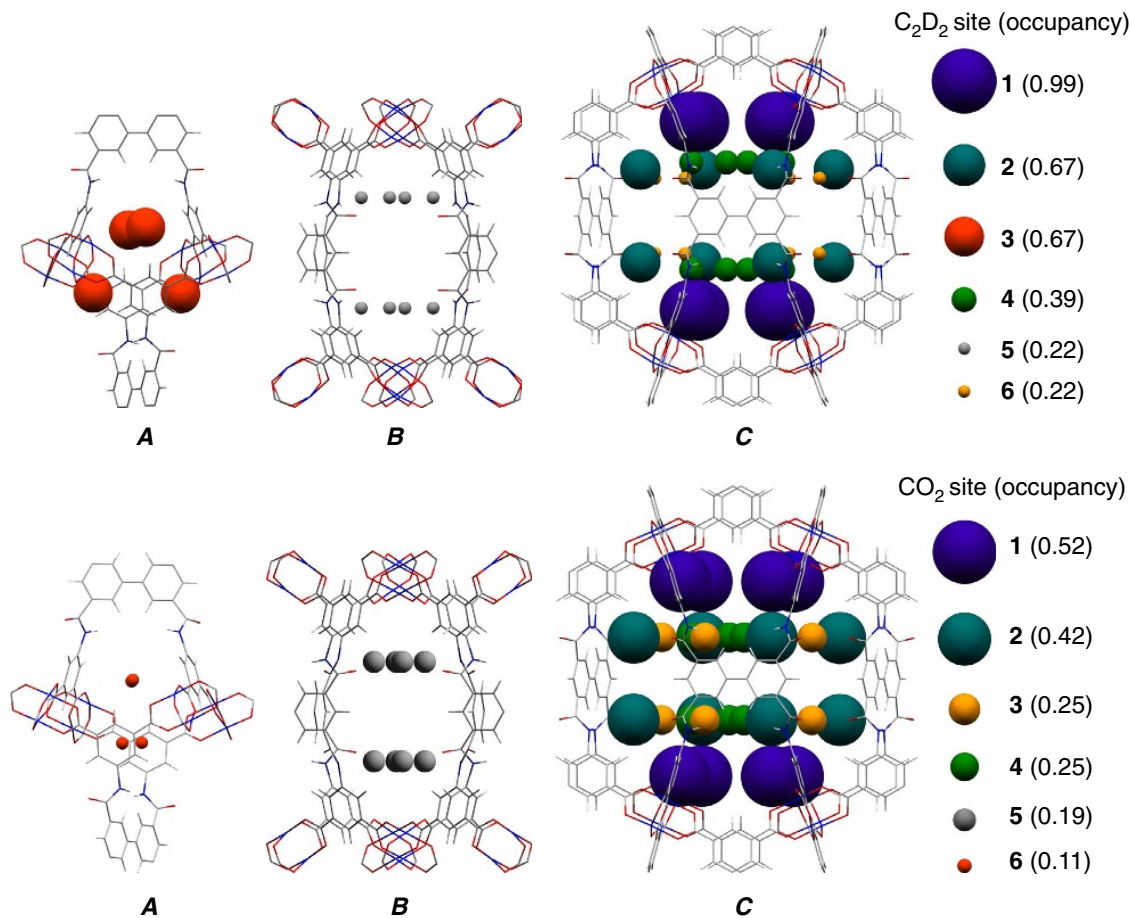

$\mathrm{CO}_{2}$ site (occupancy)

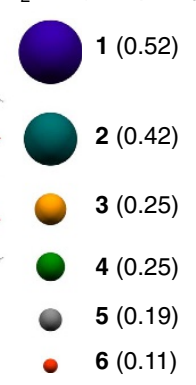

c

Figure 4 | Distribution of adsorbed gas molecules within three types of cages in MFM-188a determined from NPD data. Representation of $C_{2} D_{2}$ (top) and $\mathrm{CO}_{2}$ (bottom) positions in the cages $\boldsymbol{A}, \boldsymbol{B}$ and $\boldsymbol{C}$ of MFM-188a at a loading of $1.75 \mathrm{CO}_{2} / \mathrm{Cu}$ and $3.2 \mathrm{C}_{2} \mathrm{D}_{2} / \mathrm{Cu}$, respectively. The radii of the coloured balls figuring the various sites are proportional to corresponding crystallographic occupancies. 


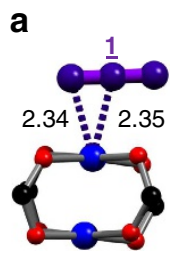

b

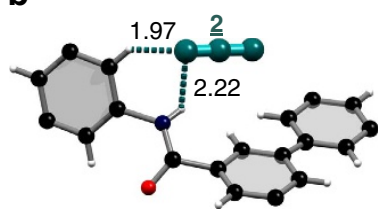

e

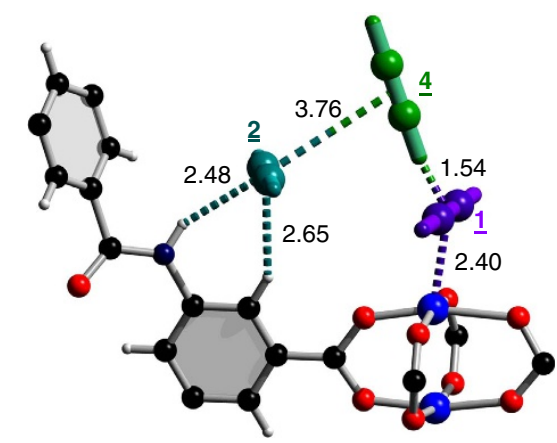

C

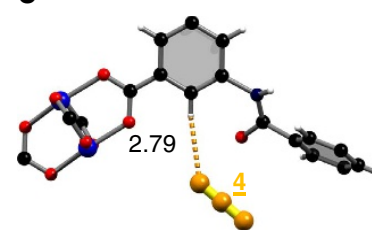

d

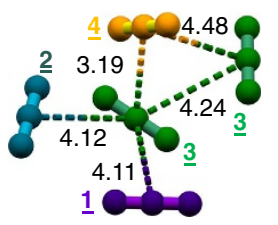

f

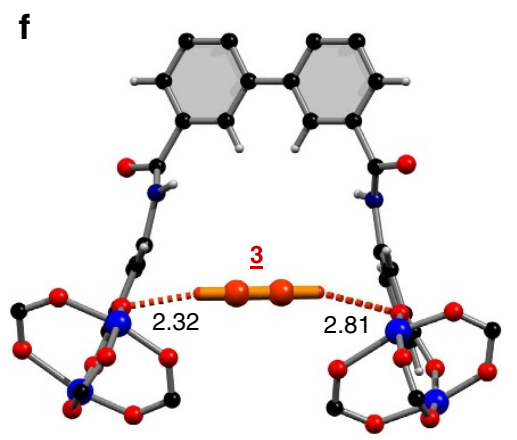

Figure 5 | Crystallographic resolution of $\mathbf{C O}_{\mathbf{2}}$ and $\mathbf{C}_{\mathbf{2}} \mathbf{H}_{\mathbf{2}}$ binding in $\mathbf{M F M - 1 8 8 a}$. Framework atoms: $\mathbf{C}$, black; $\mathrm{O}$, red; $\mathrm{H}$, white; $\mathrm{N}$, blue; $\mathrm{Cu}$, blue. Extra framework gas molecules are slightly magnified and coloured according with the binding site they occupy. Distances are shown in $\AA$. View of the binding of adsorbed $\mathrm{CO}_{2}$ molecules at site $\mathbf{1}(\mathbf{a}), \mathbf{2}(\mathbf{b})$ and $\mathbf{4}$ (c). (d) View of the packing of adsorbed $\mathrm{CO}_{2}$ molecules within cage $\boldsymbol{C}$. View of the cooperative binding of adsorbed $\mathrm{C}_{2} \mathrm{H}_{2}$ molecules at site $\mathbf{1}, \mathbf{2}, \mathbf{4}$ (e) and at site $\mathbf{3}(\mathbf{f})$.

Inelastic neutron scattering of gas-sorbent dynamics. Static crystallographic experiments are unable to gain dynamic insight into the gas-sorbent systems. To directly visualize the binding dynamics of adsorbed $\mathrm{CO}_{2}$ and $\mathrm{C}_{2} \mathrm{H}_{2}$ molecules with accessible functional groups, INS was measured for MFM-188a as a function of $\mathrm{CO}_{2}$ and $\mathrm{C}_{2} \mathrm{H}_{2}$ loading at $11 \mathrm{~K}$ (Fig. 6). The INS spectra for the bare MOF show multiple features, fully modelled via DFT calculations (Fig. 6c). The peak at $65 \mathrm{meV}$ corresponds to the out-of-plane wagging modes of the $\mathrm{N}-\mathrm{H}$ group, and peaks at 84 and $112-156 \mathrm{meV}$ originate from various deformational motions of the phenyl rings and wagging modes of aromatic $\mathrm{C}-\mathrm{H}$ groups. Comparison of the INS spectra for bare and $\mathrm{CO}_{2}$-loaded MFM-188a shows an overall stiffening effect as evidenced by a global shift of peaks to slightly higher energy (Fig. 6a). In addition, a noticeable change in the peak at $65 \mathrm{meV}$ and several small changes to the peaks between 84 and $156 \mathrm{meV}$ were observed, indicating the reduction of the motion of both amide $\mathrm{N}-\mathrm{H}$ and aromatic $\mathrm{C}-\mathrm{H}$ groups (Fig. 6d). This suggests the formation of $\mathrm{H}$-bonds between $\mathrm{CO}_{2}$ molecules and these functional groups, particularly with amide $\mathrm{N}-\mathrm{H}$ sites.

In comparison, the INS spectra of $\mathrm{C}_{2} \mathrm{H}_{2}$-loaded MFM-188a shows significant increase in intensity due to the recoil motion from the $\mathrm{H}$ atoms on adsorbed $\mathrm{C}_{2} \mathrm{H}_{2}$ (Fig. 6b). Comparison of the difference INS spectra (i.e., signals from adsorbed $\mathrm{C}_{2} \mathrm{H}_{2}$ and changes of the local MOF modes) and that of the solid $\mathrm{C}_{2} \mathrm{H}_{2}$ shows a number of interesting observations. Firstly, the low-energy INS peaks (below $25 \mathrm{meV}$, assigned as the translational modes of $\mathrm{C}_{2} \mathrm{H}_{2}$ molecules) of the difference spectra shift slightly to the lower energy region but maintain the resolved threefold peak profiles as observed in free solid $\mathrm{C}_{2} \mathrm{H}_{2}$. This indicates that the $\mathrm{C}_{2} \mathrm{H}_{2}$ molecules are ordered with restricted translational motions within MFM-188a. Secondly, the INS peaks at 80 and $95 \mathrm{meV}$ (assigned as the acetylene asymmetric and symmetric $\mathrm{C}-\mathrm{H}$ bending mode, respectively) split from a single-peak profile to a double-peak profile upon adsorption, indicating the presence of adsorbed species resulting from slightly different binding energies to the MOF host (Fig. 6f). This is in excellent agreement with the presence of the strongly bound
$\mathrm{C}_{2} \mathrm{H}_{2}$ molecules to the OMSs and free amides, and weakly bound $\mathrm{C}_{2} \mathrm{H}_{2}$ molecules to the phenyl rings and in the centre of the cages, as observed by NPD. Thirdly and most importantly, the INS peak at $65 \mathrm{meV}$ (assigned as the out-of-plane wagging modes of the $\mathrm{N}-\mathrm{H}$ group) disappears completely upon inclusion of $\mathrm{C}_{2} \mathrm{H}_{2}$ molecules in the pore, indicating loss of this mode and confirming unambiguously the direct formation of strong $\mathrm{H}$-bonds between the free amides $(\mathrm{N}-\mathrm{H})$ and $\mathrm{C}_{2} \mathrm{H}_{2}$ molecules, as found in the NPD model. This observation confirms the first example of $\mathrm{H}$-bonding between an amide group $(\mathrm{N}-\mathrm{H})$ and $\mathrm{C}_{2} \mathrm{H}_{2}$ in the solid state. Overall, the INS study is in excellent agreement with NPD results and confirms the crucial role of the free amides in the pore for gas uptakes.

\section{Discussion}

MFM-188a shows excellent performance for potential applications for $\mathrm{C}_{2} \mathrm{H}_{2}$ storage $(27.0 \mathrm{wt} \%)$ and exhibits high adsorption uptake of $\mathrm{CO}_{2}(23.7 \mathrm{wt} \%)$ under ambient conditions. A 3D plot summarising the relationship between BET surface area, density of 'OMSs + functional groups' in the structure, and uptake of $\mathrm{C}_{2} \mathrm{H}_{2}$ is shown in Fig. $3 \mathrm{c}$ for a number of the best MOFs reported to date. It is clear that to achieve high $\mathrm{C}_{2} \mathrm{H}_{2}$ uptake capacity, integration of high BET surface area (and porosity to a wider extent) and high density of binding sites in the pore structure are required. However, this is often inherently contradictory since high surface area/porosity will naturally dilute the binding sites in the pore, leading to an inevitable trade-off between these two factors. MFM-188a displays a suitably high BET surface area and high density of binding sites owing to its framework topology and pore geometry, and therefore, shows a record high $\mathrm{C}_{2} \mathrm{H}_{2}$ uptake.

Although it is widely believed that the amide groups in pores will actively participate in gas adsorption via $\mathrm{H}$-bonding, no cogent experimental evidence has been reported to date. The present study represents a unique example of a comprehensive investigation of the gas-sorbent binding interaction in a tetraamide functionalized MOF via a combination of neutron diffraction and spectroscopic techniques. These experiments offer 
a

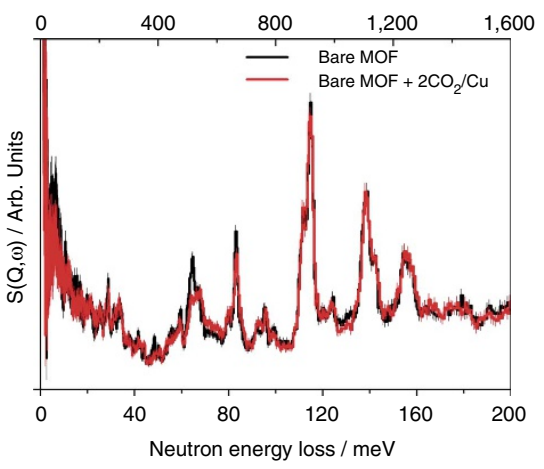

d

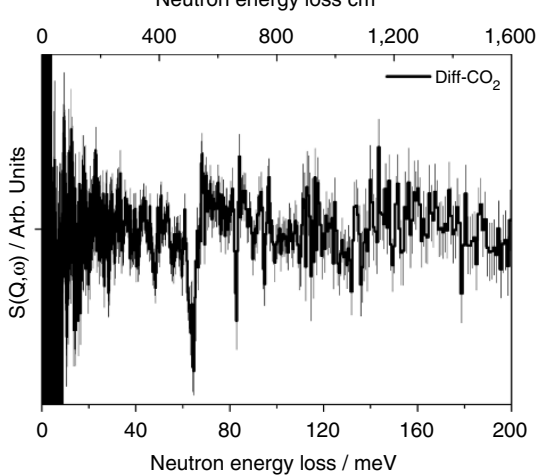

b

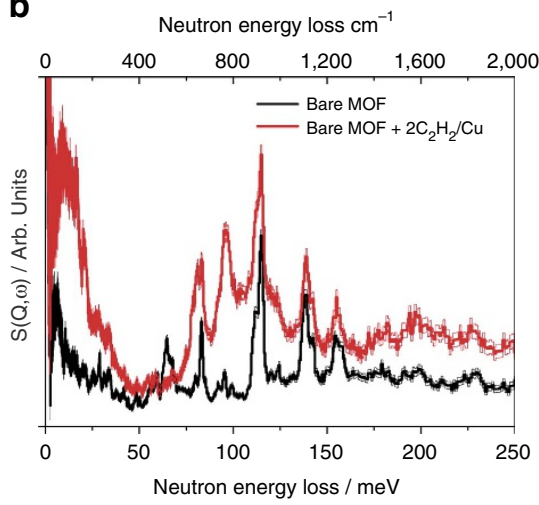

e

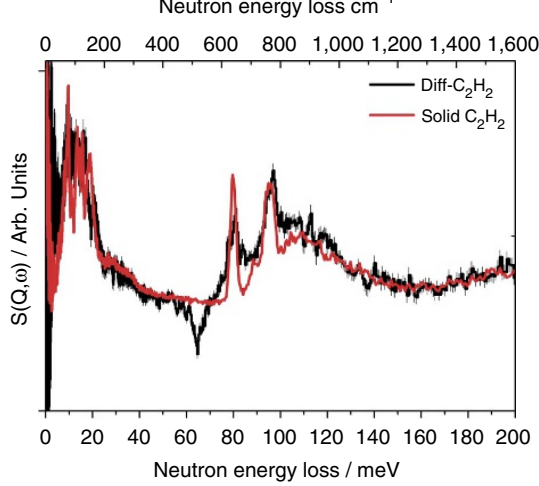

C

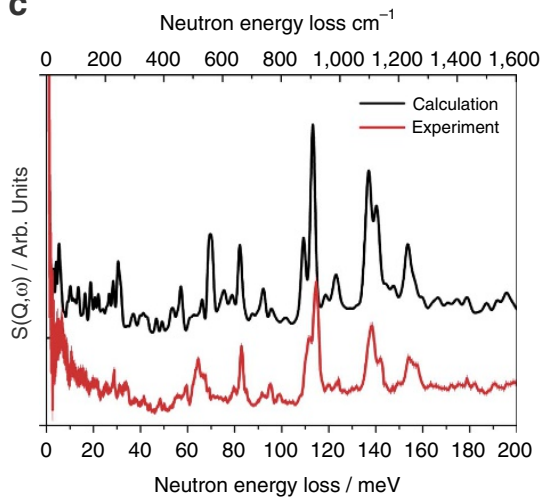

f

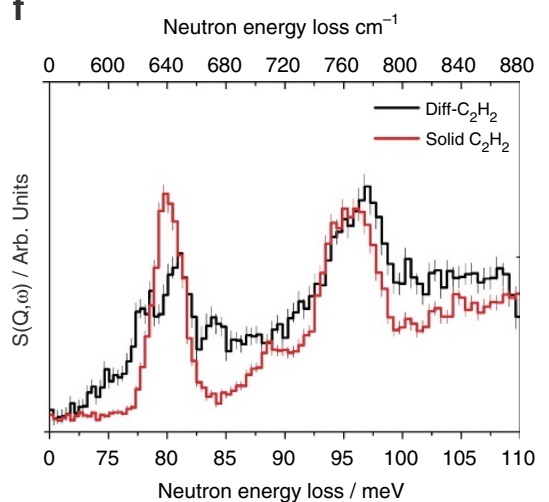

Figure 6 | INS spectra for MFM-188a as a function of guest loading. Comparison of the INS spectra for bare MFM-188a and for (a) $\mathrm{CO}_{2}$ and (b) $\mathrm{C}_{2} \mathrm{H}_{2}$-loaded MFM-188a. (c) Comparison of the experimental and DFT calculated INS spectra for MFM-188a. Comparison of the difference plots for INS spectra of bare MFM-188a and the (d) $\mathrm{CO}_{2}$ and $(\mathbf{e}) \mathrm{C}_{2} \mathrm{H}_{2}$-loaded MFM-188a, and the experimental INS spectra of condensed (e) $\mathrm{C}_{2} \mathrm{H}_{2}$ in the solid state. (f) Enlarged details for the INS spectra showing the $\mathrm{C}_{2} \mathrm{H}_{2}$ internal vibrational modes.

key insights into the molecular details of this host-guest system from both crystallographic and dynamic perspectives. A highly cooperative binding mechanism of $\mathrm{CO}_{2}$ and $\mathrm{C}_{2} \mathrm{H}_{2}$ was found on the OMSs and free amide groups in the pores of MFM-188a, with one site enhancing binding at the other. This work not only offers a new porous material for high-capacity $\mathrm{CO}_{2}$ and $\mathrm{C}_{2} \mathrm{H}_{2}$ storage, but also, more importantly, facilitates the design and structural optimization for new porous materials with improved performance in gas adsorption.

\section{Methods}

Materials and equipment. All chemical reagents and gases were obtained from commercial sources and unless otherwise noted were used without further purification. ${ }^{1} \mathrm{H}$ and ${ }^{13} \mathrm{C}$ NMR spectra were measured on a Bruker DPX 300 , AV400 or AV(III)500 spectrometers. Residual protonated species in the deuterated solvents were used as internal references. Mass spectrometry was performed on a Bruker MicroTOF with the sample dissolved in $\mathrm{MeOH}$ or $\mathrm{CH}_{3} \mathrm{CN}$. Elemental analyses were measured on a CE-440 Elemental Analyzer provided by Departmental Analytical Services at the Universities of Nottingham and Manchester. TGA was performed under a flow of air with a heating rate of $5^{\circ} \mathrm{C} \min ^{-1}$ using a Perkin Elmer Pyris 1 thermogravimetric analyser. Powder $\mathrm{X}$-ray diffraction measurements were carried out at room temperature on a PANalytical X'Pert PRO diffractometer using $\mathrm{Cu}-\mathrm{K} \alpha$ radiation $\left(\lambda=1.5418 \AA \AA^{\prime}\right)$ at a scan speed of $0.02^{\circ} \mathrm{s}^{-1}$ and a step size of $0.02^{\circ}$ in $2 \theta$.

Preparation of $\mathbf{H}_{\mathbf{8}} \mathbf{L}$. [1, $1^{\prime}$-biphenyl]-3,3',5,5'-tetracarboxylic acid (3.0 g, $9.1 \mathrm{mmol}$ ) was suspended in $200 \mathrm{ml}$ of dry THF and thionyl chloride $(10 \mathrm{ml}, 137.8 \mathrm{mmol})$ was added dropwise under inert atmosphere. The resulting mixture was refluxed under inert atmosphere for $16 \mathrm{~h}$. After cooling, the solvent and excess thionyl chloride were evaporated under reduced pressure affording $\left[1,1^{\prime}\right.$-biphenyl]-3,3',5,5' -tetracarbonyl tetrachloride as an off white solid, which was dried under vacuum for $2 \mathrm{~h}$ and dissolved in $200 \mathrm{ml}$ of dry THF. The [1,1'-biphenyl]-3,3',5,5'-tetracarbonyl tetrachloride solution was added by cannula to a solution of 5-aminoisophthalic acid $(9.84 \mathrm{~g}, 54.3 \mathrm{mmol})$ in $250 \mathrm{ml}$ of dry THF and trimethylamine $(3.7 \mathrm{ml}, 27.4 \mathrm{mmol})$ was added slowly. The resulting suspension was stirred under inert atmosphere for $2 \mathrm{~h}$. Aqueous $\mathrm{HCl}(2 \mathrm{M}, 200 \mathrm{ml})$ was added and THF evaporated under reduced pressure. The resulting solid was isolated by filtration, washed successively with water and hot $\mathrm{MeOH}$ and dried under vacuum to afford $\mathrm{H}_{8} \mathrm{~L}$ as an off-white powder $(7.65 \mathrm{~g}, 85.5 \%) .{ }^{1} \mathrm{H}$ NMR: $\left(300 \mathrm{MHz}, \mathrm{DMSO}-\mathrm{d}_{6}\right) \delta=12.98$ (bs, $\left.8 \mathrm{H}, \mathrm{COOH}\right), 11.07$ (bs, $\left.4 \mathrm{H}, \mathrm{NH}\right), 8.83$ (bm, $14 \mathrm{H}, \mathrm{ArH}), 8.33$ (bs, $4 \mathrm{H}, \mathrm{ArH}) ;{ }^{13} \mathrm{C}$ NMR: $\left(126 \mathrm{MHz}, \mathrm{CDCl}_{3}\right), \delta=167.0$ (CO), $165.5(\mathrm{CO}), 140.2(\mathrm{C}), 140.0(\mathrm{C}), 136.1(\mathrm{C}), 132.2(\mathrm{C}), 130.1(\mathrm{CH}), 127.6$ (CH), $125.7(\mathrm{CH}), 125.3(\mathrm{CH})$; MS: (ESI): $m / z=981.31(\mathrm{M}-\mathrm{H})^{-}$.

Preparation of MFM-188. $\mathrm{H}_{8} \mathrm{~L}(165 \mathrm{mg}, 0.168 \mathrm{mmol})$ and $\mathrm{CuCl}_{2}$ $(0.225 \mathrm{~g}, 1.675 \mathrm{mmol})$ were dissolved in dimethyl sulfoxide $(8 \mathrm{ml}) . \mathrm{N}, \mathrm{N}^{\prime}$-diethylformamide $(16 \mathrm{ml})$, EtOH $(16 \mathrm{ml})$ and aqueous $\mathrm{HCl}(8 \mathrm{ml}, 0.1 \mathrm{M})$ were added to the resulting solution, which was placed in a tightly capped $250 \mathrm{ml}$ Duran pressure plus laboratory bottle. The solution was heated at $80^{\circ} \mathrm{C}$ in an oven for $96 \mathrm{~h}$, and a large amount of crystalline product precipitated. The blue crystal plates were isolated by filtration while the mother solution was still warm and washed sequentially with warm DMF and $\mathrm{MeOH}$, and stored under $\mathrm{MeOH}$ (yield based on TGA of as synthesized material: $0.172 \mathrm{~g}, 64 \%$, see Supplementary Fig. 11). After activation and rehydration, $\left[\mathrm{Cu}_{4} \mathrm{~L}\left(\mathrm{H}_{2} \mathrm{O}\right)_{4}\right] \cdot 12 \mathrm{H}_{2} \mathrm{O}$ was obtained; elemental analysis: calculated/found: C, 39.90/40.16; H, 3.21/3.24; N, 3.88/3.79.

Material activation procedure. Aquamarine crystals of MFM-188 were solvent-exchanged with $\mathrm{MeOH}$ for 3 days, replacing with fresh $\mathrm{MeOH}$ twice a day. The $\mathrm{MeOH}$ exchanged samples were first activated by flowing supercritical $\mathrm{CO}_{2}$ for $12 \mathrm{~h}$, upon which the colour changed to purple, then transferred to a glovebox under $\mathrm{N}_{2}$. The $\mathrm{scCO}_{2}$ dried samples were then transferred onto the gas adsorption instruments under inert atmosphere and heated at $100^{\circ} \mathrm{C}$ under dynamic vacuum for $20 \mathrm{~h}$.

Single crystal X-ray diffraction structure determination. A single crystal diffraction data set for MFM-188 was collected at $120 \mathrm{~K}$ using an Agilent 
GV1000 diffractometer $(\lambda=1.54056 \AA)$. Details of data collection and processing procedures are included in the CIF files. Structures were solved by direct methods using SHELXS ${ }^{31}$ and remaining atoms were localized from successive difference Fourier maps using SHELXL ${ }^{32}$. The hydrogen atoms from the linkers and the coordinated water molecules were placed geometrically and refined using a riding model. The refinement of the framework was performed by ignoring the contribution of the disordered solvent molecules. The region containing the disordered electron density was identified by considering the van der Waals radii of the atoms constituting the ordered framework. The contribution of this region to the total structure factor was calculated via a discrete Fourier transformation and subtracted in order to generate a new set of $h k l$ reflections by means of the program SQUEEZE ${ }^{33}$. Acquisition and final refinement data are summarized in Supplementary Table 1.

Gas sorption measurements. Volumetric $\mathrm{N}_{2}, \mathrm{CO}_{2}$ and $\mathrm{C}_{2} \mathrm{H}_{4}$ isotherms for pressures in the range $0-1$ bar were determined using a Micromeritics 3-Flex apparatus. Ultra-high purity $\mathrm{He}(99.999 \%)$, for void volume determination, $\mathrm{N}_{2}$ (99.999\%), $\mathrm{CO}_{2}$ (99.999\%) were purchased from BOC and used as received. $\mathrm{C}_{2} \mathrm{H}_{2}$ gas was filtered through $4 \mathrm{~A}$ molecular sieves and activated carbon to remove traces of acetone. Pore size distribution data for MFM-188a was determined by analysing the $\mathrm{N}_{2}$ isotherm at $77 \mathrm{~K}$ using a non-local density functional theory based on a carbon model containing cylindrical pores as implemented in the 3-Flex software package.

The $\mathrm{CO}_{2}$ adsorption isotherms at 273 and $298 \mathrm{~K}$ as well the $\mathrm{C}_{2} \mathrm{H}_{2}$ isotherms at 273 and $295 \mathrm{~K}$ were fitted to the virial equation (1). $P$ is the pressure expressed in bars, $N$ is the amount expressed in molg ${ }^{-1}, T$ is the temperature in K, $a_{i}$ and $b_{j}$ are virial coefficients and $m, n$ represent the number of coefficients. The values of the virial coefficients $a_{0}$ to $a_{m}$ were then used to calculate the isosteric heat of adsorption using equation (2). $Q_{s t}$ is the coverage dependent isosteric heat of adsorption and $\mathrm{R}$ is the universal gas constant.

$$
\begin{gathered}
\ln (P)=\ln (N)+(1 / T) \sum_{i=0}^{m} a_{i} N^{i}+\sum_{j=0}^{n} b_{j} N^{j} \\
Q_{\mathrm{st}}=-R \sum_{i=0}^{m} a_{i} N^{i}
\end{gathered}
$$

To evaluate the $\mathrm{CO}_{2} / \mathrm{N}_{2}$ selectivity of MFM-188a, the $\mathrm{N}_{2}$ isotherm was also measured at $298 \mathrm{~K}$ (Supplementary Fig. 12) up to 1 bar. By determining the ratios of the Henry's law constants from single-component isotherms, the $\mathrm{CO}_{2} / \mathrm{N}_{2}$ adsorption selectivity for MFM-188a is estimated as 22.5 at $298 \mathrm{~K}$. It is worth noting that this selectivity carries large uncertainty because of the very low $\mathrm{N}_{2}$ uptake measured under these conditions.

Neutron powder diffraction. NPD experiments were carried out at WISH, a long wavelength powder and single crystal neutron diffractometer at the ISIS Facility at the Rutherford Appleton Laboratory (UK) ${ }^{34}$. MFM-188 was loaded into a $6 \mathrm{~mm}$ diameter vanadium sample can and outgassed at $1 \times 10^{-7} \mathrm{mbar}$ and $100^{\circ} \mathrm{C}$ for 1 day. The sample was loaded into a liquid helium cryostat and cooled to $7 \mathrm{~K}$ for data collection. $\mathrm{CO}_{2}$ and $\mathrm{C}_{2} \mathrm{D}_{2}$ gas was introduced by warming the samples to $290 \mathrm{~K}$, and the gas dosed volumetrically from a calibrated volume. The gas-loaded sample was then cooled to $7 \mathrm{~K}$ over a period of $2 \mathrm{~h}$ to ensure good mobility of adsorbed $\mathrm{CO}_{2} / \mathrm{C}_{2} \mathrm{D}_{2}$ within the crystalline structure of MFM-188a. The sample was kept at $7 \mathrm{~K}$ for an additional 30 mins before data collection to ensure the thermal equilibrium. The structure solution was initially established by considering the structure of the bare MFM-188a, and the residual nuclear density maps were further developed from subsequent difference Fourier analysis using TOPAS program Acquisition and refinement data are summarized in Supplementary Table 2.

Inelastic neutron scattering. INS spectra were recorded on the TOSCA spectrometer at the ISIS Facility at the Rutherford Appleton Laboratory (UK) for energy transfers between $\sim-2$ and $500 \mathrm{meV}$. In this region TOSCA has a resolution of $1.5 \% \Delta E / E$. Before INS experiments, MeOH exchanged MFM-188 was activated by flowing supercritical $\mathrm{CO}_{2}$ for $12 \mathrm{~h}$, the desolvated sample was then transferred in a glovebox under inert atmosphere, and $0.5 \mathrm{~g}$ of activated MFM-188a were placed in a closed cylindrical vanadium sample cell with an indium seal. The sample was further degassed at $100^{\circ} \mathrm{C}$ under dynamic vacuum for $20 \mathrm{~h}$ to remove traces of adsorbed guest species.

The temperature during data collection was controlled using a closed cycle refrigerator cryostat $(11 \pm 0.1 \mathrm{~K})$. The loading of $2 \mathrm{C}_{2} \mathrm{H}_{2} / \mathrm{Cu}$ and $2 \mathrm{CO}_{2} / \mathrm{Cu}$ was performed volumetrically at room temperature to ensure that $\mathrm{C}_{2} \mathrm{H}_{2}$ and $\mathrm{CO}_{2}$ were present in the gas phase when not adsorbed and also to ensure sufficient mobility of $\mathrm{C}_{2} \mathrm{H}_{2}$ and $\mathrm{CO}_{2}$ inside the MFM-188a framework. Subsequently, the temperature was reduced to $7 \mathrm{~K}$ for data collection. Background spectra (sample can plus MFM-188a) were subtracted to obtain the difference spectra. INS spectra for condensed $\mathrm{C}_{2} \mathrm{H}_{2}$ and $\mathrm{CO}_{2}$ in the solid state were measured by using a plate sample container. Approximately $1-21$ of each gas at room temperature was condensed slowly at temperatures below their melting points and cooled to temperature below $10 \mathrm{~K}$ for neutron scattering measurements.

DFT calculations and modelling of the INS spectra. Periodic density functional theory (periodic-DFT) calculations were carried out using the plane-wave pseudopotential method as implemented in the CASTEP code 55,36 . Exchange and correlation were approximated using the PBE functional ${ }^{37}$. For MFM-188 the structure determined by NPD was used as the initial structure. The plane-wave cutoff energy was $750 \mathrm{eV}$ using on-the-fly generated pseudopotentials and spin polarized calculations were carried out. Owing to the size of the unit cell $\left(12106 \AA^{-3}\right)$, Brillouin zone sampling of electronic states was performed on $4 \times 4 \times 1$ Monkhorst-Pack grid. The equilibrium structure, an essential prerequisite for lattice dynamics calculations was obtained by BFGS geometry optimization after which the residual forces were converged to zero within $0.007 \mathrm{eV} \AA^{-1}$. Phonon frequencies were obtained by diagonalization of dynamical matrices computed using density functional perturbation theory ${ }^{38}$. The atomic displacements in each mode that are part of the CASTEP output enable visualization of the modes to aid assignments and are also all that is required to generate the INS spectrum using the program ACLIMAX ${ }^{39}$. It was found that even with these stringent convergence conditions, there were five imaginary modes. It is emphasized that for all the calculated spectra shown the transition energies have not been scaled.

Data availability. The X-ray crystallographic coordinates for structures reported in this Article have been deposited at the Cambridge Crystallographic Data Center (CCDC), under deposition numbers 1496263 (as-synthesized MFM-188), 1504308 (desolvated MFM-188a), $1496264\left(\mathrm{C}_{2} \mathrm{D}_{2}\right.$-loaded MFM-188) and 1496265 $\left(\mathrm{CO}_{2}\right.$-loaded MFM-188). These data can be obtained free of charge from The Cambridge Crystallographic Data Center via www.ccdc.cam.ac.uk/data_request/cif, all other data are available from the corresponding authors upon request.

\section{References}

1. Yan, Y., Yang, S., Blake, A. J. \& Schröder, M. Studies on metal-organic frameworks of $\mathrm{Cu}(\mathrm{II})$ with isophthalate linkers for hydrogen storage. Acc. Chem. Res. 47, 296-307 (2014).

2. He, Y., Zhou, W., Qian, G. \& Chen, B. Methane storage in metal-organic frameworks. Chem. Soc. Rev. 43, 5657-5678 (2014).

3. Barea, E., Montoro, C. \& Navarro, J. A. R. Toxic gas removal-metal-organic frameworks for the capture and degradation of toxic gases and vapours. Chem Soc. Rev. 43, 5419-5430 (2014).

4. $\mathrm{Hu}, \mathrm{Z}$., Deibert, B. J. \& Li, J. Luminescent metal-organic frameworks for chemical sensing and explosive detection. Chem. Soc. Rev. 43, 5815-5840 (2014).

5. Liu, J. et al. Applications of metal-organic frameworks in heterogeneous supramolecular catalysis. Chem. Soc. Rev. 43, 6011-6061 (2014).

6. Ramaswamy, P., Wong, N. E. \& Shimizu, G. K. H. MOFs as proton conductors-challenges and opportunities. Chem. Soc. Rev. 43, 5913-5932 (2014).

7. Yang, S. et al. Supramolecular binding and separation of hydrocarbons within a functionalized porous metal-organic framework. Nat. Chem. 7, 121-129 (2014).

8. Lin, X. et al. High capacity hydrogen adsorption in $\mathrm{Cu}(\mathrm{II})$ tetracarboxylate framework materials: the role of pore size, ligand functionalization, and exposed metal sites. J. Am. Chem. Soc. 131, 2159-2171 (2009).

9. Yan, Y. et al. Metal-organic polyhedral frameworks: high $\mathrm{H}_{2}$ adsorption capacities and neutron powder diffraction studies. J. Am. Chem. Soc. 132, 4092-4094 (2010).

10. Queen, W. L. et al. Site-specific $\mathrm{CO}_{2}$ adsorption and zero thermal expansion in an anisotropic pore network. J. Phys. Chem. C 115, 24915-24919 (2011).

11. Pang, J. et al. A porous metal-organic framework with ultrahigh acetylene uptake capacity under ambient conditions. Nat. Commun. 6, 7575 (2015).

12. Bloch, E. D. et al. Hydrocarbon separations in a metal-organic framework with open iron(II) coordination sites. Science 335, 1606-1610 (2012).

13. Wu, H., Zhou, W. \& Yildirim, T. High-capacity methane storage in metalorganic frameworks $\mathrm{M}_{2}$ (dhtp) : the important role of open metal sites. J. Am. Chem. Soc. 131, 4995-5000 (2009).

14. Bloch, E. D. et al. Hydrogen storage and selective, reversible $\mathrm{O}_{2}$ adsorption in a metal-organic framework with open chromium(II) sites. Angew Chem. Int. Ed. Engl. 55, 8605-8609 (2016).

15. Callear, S. K., Ramirez-Cuesta, A. J., David, W. I. F., Millange, F. \& Walton, R. I. High-resolution inelastic neutron scattering and neutron powder diffraction study of the adsorption of dihydrogen by the $\mathrm{Cu}(\mathrm{II})$ metal-organic framework material HKUST-1. Chem. Phys. 427, 9-17 (2013).

16. Vaidhyanathan, R. et al. Direct observation and quantification of $\mathrm{CO}_{2}$ binding within an amine-functionalized nanoporous solid. Science 330, 650-653 (2010).

17. Lin, J.-B., Xue, W., Zhang, J.-P. \& Chen, X.-M. An ionic porous coordination framework exhibiting high $\mathrm{CO}_{2}$ affinity and $\mathrm{CO}_{2} / \mathrm{CH}_{4}$ selectivity. Chem. Commun. 47, 926-928 (2011). 
18. Liao, P.-Q. et al. Strong and dynamic $\mathrm{CO}_{2}$ sorption in a flexible porous framework possessing guest chelating claws. J. Am. Chem. Soc. 134, 17380-17383 (2012).

19. Alsmail, N. H. et al. Analysis of high and selective uptake of $\mathrm{CO}_{2}$ in an oxamide-containing $\left\{\mathrm{Cu}_{2}(\mathrm{OOCR})_{4}\right\}$-based metal-organic framework. Chem. Eur. J. 20, 7317-7324 (2014).

20. Xiang, Z., Leng, S. \& Cao, D. Functional group modification of metal-organic frameworks for $\mathrm{CO}_{2}$ capture. J. Phys. Chem. C 116, 10573-10579 (2012).

21. $\mathrm{Hu}, \mathrm{T}$.-L. et al. Microporous metal-organic framework with dual functionalities for highly efficient removal of acetylene from ethylene/acetylene mixtures. Nat. Commun. 6, 7328 (2015).

22. Zheng, B., Bai, J., Duan, J., Wojtas, L. \& Zaworotko, M. J. Enhanced $\mathrm{CO}_{2}$ binding affinity of a high-uptake rht -type metal-organic framework decorated with acylamide groups. J. Am. Chem. Soc. 133, 748-751 (2011).

23. Zhang, M. et al. Finely tuning MOFs towards high performance in $\mathrm{C}_{2} \mathrm{H}_{2}$ storage: synthesis and properties of a new MOF-505 analogue with an inserted amide functional group. Chem. Commun. 52, 7241-7244 (2016).

24. Lu, W., Yuan, D., Makal, T. A., Li, J.-R. \& Zhou, H.-C. A highly porous and robust $(3,3,4)$-connected metal-organic framework assembled with a $90^{\circ}$ bridging-angle embedded octacarboxylate ligand. Angew Chem. Int. Ed. Engl. 51, 1580-1584 (2012).

25. Spek, A. L. Structure validation in chemical crystallography. Acta Crystallogr D Biol. Crystallogr. 65, 148-155 (2009).

26. Farha, O. K. et al. Metal-organic framework materials with ultrahigh surface areas: is the sky the limit? J. Am. Chem. Soc. 134, 15016-15021 (2012).

27. Caskey, S. R., Wong-Foy, A. G. \& Matzger, A. J. Dramatic tuning of carbon dioxide uptake via metal substitution in a coordination polymer with cylindrical pores. J. Am. Chem. Soc. 130, 10870-10871 (2008).

28. Xiang, S., Zhou, W., Gallegos, J. M., Liu, Y. \& Chen, B. Exceptionally high acetylene uptake in a microporous metal-organic framework with open metal sites. J. Am. Chem. Soc. 131, 12415-12419 (2009).

29. Cui, X. et al. Pore chemistry and size control in hybrid porous materials for acetylene capture from ethylene. Science 353, 141-144 (2016).

30. Li, B. et al. Enhanced binding affinity, remarkable selectivity, and high capacity of $\mathrm{CO}_{2}$ by dual functionalization of a rht-type metal-organic framework. Angew. Chem. Int. Ed. Engl. 51, 1412-1415 (2012).

31. Sheldrick, G. M. A short history of SHELX. Acta Crystallogr. A 64, 112-122 (2008).

32. Sheldrick, G. M. Crystal structure refinement with SHELXL. Acta Crystallogr. C Struct. Chem. 71, 3-8 (2015).

33. Spek, A. L. PLATON SQUEEZE: a tool for the calculation of the disordered solvent contribution to the calculated structure factors. Acta Crystallogr. C Struct. Chem. 71, 9-18 (2015).

34. Chapon, L. C. et al. Wish: the new powder and single crystal magnetic diffractometer on the second target station. Neutron News 22, 22-25 (2011).

35. Clark, S. J. et al. First principles methods using CASTEP. Z. Für. Krist. Cryst. Mater. 220, 567-570 (2005)

36. Refson, K., Tulip, P. R. \& Clark, S. J. Variational density-functional perturbation theory for dielectrics and lattice dynamics. Phys. Rev. B 73, 155114 (2006).

37. Perdew, J. P., Burke, K. \& Ernzerhof, M. Generalized gradient approximation made simple. Phys. Rev. Lett. 77, 3865-3868 (1996).

38. Milman, V. et al. Structural, electronic and vibrational properties of tetragonal zirconia under pressure: a density functional theory study. J. Phys. Condens. Matter 21, 485404 (2009).

39. Ramirez-Cuesta, A. J. aCLIMAX 4.0.1, The new version of the software for analyzing and interpreting INS spectra. Comput. Phys. Commun. 157, 226-238 (2004).

40. Xiang, S. et al. Open metal sites within isostructural metal-organic frameworks for differential recognition of acetylene and extraordinarily high acetylene storage capacity at room temperature. Angew. Chem. Int. Ed. Engl. 49, 4615-4618 (2010).
41. Wen, H.-M. et al. A microporous metal-organic framework with lewis basic nitrogen sites for high $\mathrm{C}_{2} \mathrm{H}_{2}$ storage and significantly enhanced $\mathrm{C}_{2} \mathrm{H}_{2} / \mathrm{CO}_{2}$ separation at ambient conditions. Inorg. Chem. 55, 7214-7218 (2016).

42. Burd, S. D. et al. Highly selective carbon dioxide uptake by $[\mathrm{Cu}(\mathrm{bpy}-$ $\left.n)_{2}\left(\mathrm{SiF}_{6}\right)\right]\left(\right.$ bpy-1 $=4,4^{\prime}$-Bipyridine; bpy-2=1,2-Bis(4-pyridyl)ethane). J. Am. Chem. Soc. 134, 3663-3666 (2012).

43. Cai, J. et al. An amino-decorated NbO-type metal-organic framework for high $\mathrm{C}_{2} \mathrm{H}_{2}$ storage and selective $\mathrm{CO}_{2}$ capture. RSC Adv. 5, 77417-77422 (2015).

44. He, Y., Krishna, R. \& Chen, B. Metal-organic frameworks with potential for energy-efficient adsorptive separation of light hydrocarbons. Energy Environ. Sci. 5, 9107 (2012).

45. Duan, X. et al. A novel metal-organic framework for high storage and separation of acetylene at room temperature. J. Solid State Chem. 241, 152-156 (2016).

46. Wen, H.-M. et al. A microporous metal-organic framework with rare $l v t$ topology for highly selective $\mathrm{C}_{2} \mathrm{H}_{2} / \mathrm{C}_{2} \mathrm{H}_{4}$ separation at room temperature. Chem. Commun. 51, 5610-5613 (2015).

\section{Acknowledgements}

We thank EPSRC, ERC and Universities of Manchester and Nottingham for funding. N.H.A.S. thanks the Royal Commission for Jubail and Yanbu, Jubail University College, Kingdom of Saudi Arabia for a PhD Fellowship. We are especially grateful to STFC and the ISIS Neutron Facility for access to the Beamlines TOSCA and WISH. We thank Dr Svemir Rudić for his help at ISIS. Computing resources (time on the SCARF compute cluster for the CASTEP calculations) was provided by the STFC e-Science facility.

\section{Author contributions}

Synthesis and characterization of MOF samples was done by F.M., T.L.E. and N.H.A.S Measurements and analysis of adsorption isotherms, collection and analysis of single crystal structures was done by F.M.; F.M., I.d.S., H.G.W.G., M.Sav., S.F.P., P.M. and S.Y. did the collection and analysis of neutron scattering data. S.Y. and M.Sch. did overall direction, design and development of project. F.M., S.Y. and M.Sch. with all other authors prepared the manuscript.

\section{Additional information}

Supplementary Information accompanies this paper at http://www.nature.com/ naturecommunications

Competing financial interests: The authors declare no competing financial interests.

Reprints and permission information is available online at http://npg.nature.com/ reprintsandpermissions/

How to cite this article: Moreau, F. et al. Unravelling exceptional acetylene and carbon dioxide adsorption within a tetra-amide functionalized metal-organic framework. Nat. Commun. 8, 14085 doi: 10.1038/ncomms14085 (2017).

Publisher's note: Springer Nature remains neutral with regard to jurisdictional claims in published maps and institutional affiliations.

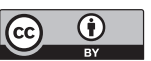

This work is licensed under a Creative Commons Attribution 4.0 International License. The images or other third party material in this article are included in the article's Creative Commons license, unless indicated otherwise in the credit line; if the material is not included under the Creative Commons license, users will need to obtain permission from the license holder to reproduce the material. To view a copy of this license, visit http://creativecommons.org/licenses/by/4.0/

(C) The Author(s) 2017 